EPJ Web of Conferences 75, 05005 (2014)

DOI: 10.1051/epjconf/ 20147505005

(C) Owned by the authors, published by EDP Sciences, 2014

\title{
Structural Modification and Self-Assembly of Nanoscale Magnetite Synthesised in the Presence of an Anionic Surfactant.
}

\author{
S. Malik ${ }^{1, \mathrm{a}}$, I. J. Hewitt ${ }^{2}$, and A. K. Powell ${ }^{1,2}$ \\ ${ }^{1}$ Institute of Nanotechnology, Karlsruhe Institute of Technology, D-76131 Karlsruhe, Germany \\ ${ }^{2}$ Institute of Inorganic Chemistry, Karlsruhe Institute of Technology, D-76131 Karlsruhe, Germany
}

\begin{abstract}
The earliest reported medical use of magnetite powder for internal applications was in the 10th century A.D. by the Persian physician and philosopher Avicenna of Bokhara [1,2]. Today magnetic nanoparticles are used for magnetic resonance imaging (MRI) and are potential colloidal mediators for cancer magnetic hyperthermia [3]. Twenty years ago magnetite $\left(\mathrm{Fe}_{3} \mathrm{O}_{4}\right)$ was found to be present in the human brain [4] and more recently it has been reported that nanoscale biogenic magnetite (origin and formation uncertain) is associated with neurodegenerative diseases such as Parkinson's, Huntington's and Alzheimer's [5]. Here we show that the synthesis of magnetite in the presence of the surfactant sodium dodecyl sulphate (SDS) gives rise to a variety of nanoscale morphologies, some of which look remarkably similar to magnetite found in organisms, suggesting that similar processes may be involved. Furthermore, these 1D materials with diameters of quantum confined size are of interest in the areas of biosensors [6] and biomedical imaging [7].
\end{abstract}

\section{Introduction}

The average human body contains ca. $4-5 \mathrm{~g}$ of iron which is stored within ferritin [8] - a hollow spherical protein shell $12 \mathrm{~nm}$ in diameter and capable of holding up to 4500 iron atoms in the form of an $8 \mathrm{~nm}$ ferrihydrite $\left(5 \mathrm{Fe}_{2} \mathrm{O}_{3} \cdot 9 \mathrm{H}_{2} \mathrm{O}\right)$ particle, which is biomineralized in the protein core. There is no active mechanism for iron excretion in humans and excess iron can accumulate in certain organs. A striking correlation between the amount of nanoscale biogenic magnetite in diseased brain tissue and the onset and progression of Alzheimer's disease has recently been reported [5]. Although the origin and formation of this magnetite is not certain there is evidence from studies on magnetotactic bacteria [9] that the biogenic magnetite present there has a ferrihydrite precursor [10].

In magnetotactic bacteria, these biogenically controlled morphologies of magnetite occur in the form of nanocrystals. These have been found to have elongated $\{1,1,1\}$ axes often with rhombic or truncated dodecahedral morphology. They occur in intracellular structures called magnetosomes [11]. A magnetosome consists of a nanocrystal surrounded by a lipid bilayer membrane. They arrange in a 1D array to form a "compass needle" which is utilised by the bacteria to sense the Earth's magnetic field [12, 13].

Taking this lead from biology, where the biogenic templates produce magnetite of defined shapes and sizes, we have been interested in investigating how surfactant molecules could similarly influence magnetite formation where the SDS micelles act as analogues for the bacterial magnetosome envelope. In our experiments we find hydrothermal conditions can be used to produce normal, octahedral magnetite in the absence of SDS (figure 1), such as is observed under geological conditions (figure 2).

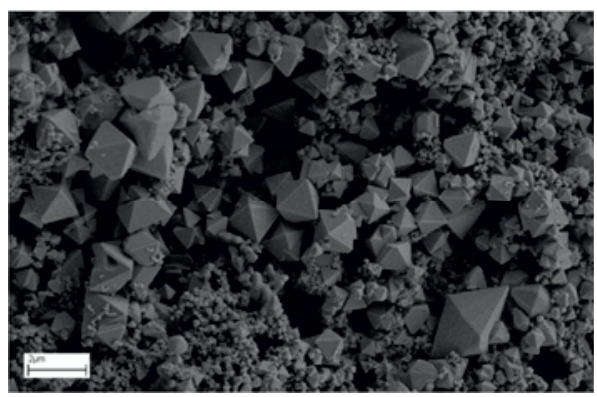

Figure 1. Octahedrally shaped magnetite. Scanning electron micrograph of magnetite formed hydrothermally without SDS present.

\footnotetext{
${ }^{\mathrm{a}}$ Corresponding author: sharali.malik@kit.edu
} 
However, when the surfactant sodium dodecyl sulfate, SDS (figure 3) is present we find instead a variety of magnetite morphologies which appear to have biogenic trademarks. SDS is commonly used to mimic hydrophobic binding environments such as cell membranes [14], and has recently been used to study the folding and thermal stability of cytochrome c (cyt c) which is a biologically important electron transfer system [15].

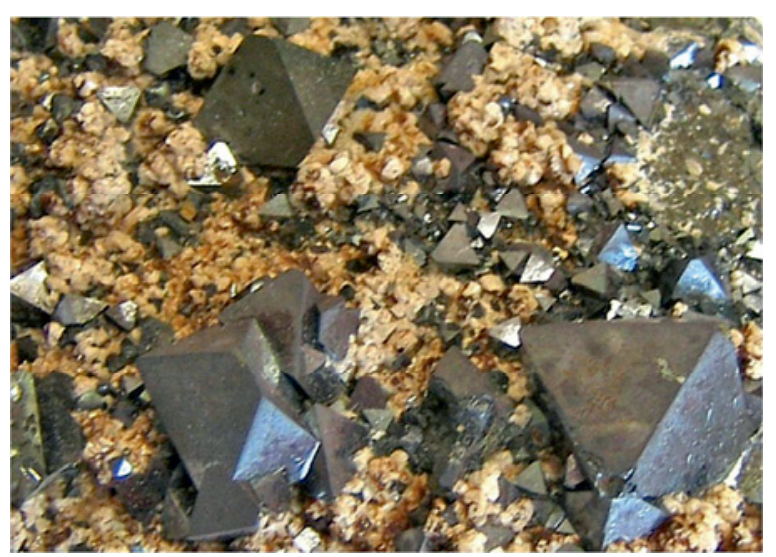

Figure 2. Geological octahedrally shaped magnetite crystallised on feldspar and quartz found in Bolivia (photo by A.K. Powell).

Scanning electron microscopy (SEM) and transmission electron microscopy (TEM) were used to observe the morphologies of magnetite formed. The synthesis of magnetite in the presence of SDS under hydrothermal conditions has yielded a variety of structures, five of which are discussed here.

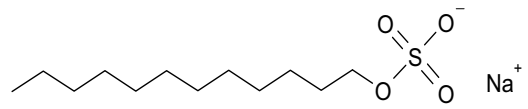

Figure 3. The anionic surfactant SDS

\section{Experimental}

All chemicals were reagent grade and used without further purification. Ferrous chloride tetrahydrate $\left(\mathrm{FeCl}_{2} \cdot 4 \mathrm{H}_{2} \mathrm{O}>99 \%\right)$, sodium hydroxide $(\mathrm{NaOH}>97 \%)$ and sodium dodecyl sulphate (SDS $>99 \%$ ) were obtained from Sigma-Aldrich. Double-distilled water, sodium hydroxide solutions and SDS solutions were deoxygenated by bubbling $\mathrm{N}_{2}$ gas for $1 \mathrm{hr}$ prior to use. The synthesis of magnetite was performed under nitrogen in an autoclave using a $20 \mathrm{ml}$ Teflon insert.

Compounds 1-5: To an aqueous solution containing $\mathrm{FeCl}_{2} \cdot 4 \mathrm{H}_{2} \mathrm{O}$ and SDS a deoxygenated aqueous $\mathrm{NaOH}$ solution was added, see Table 1 for quantities and concentrations. The autoclave was heated at $200^{\circ} \mathrm{C}$ for $24 \mathrm{~h}$ and after cooling the magnetite was isolated as detailed in section (b).
Table 1. Reagent quantities and concentrations used to make compounds $1-5$

\begin{tabular}{|l|l|l|l|}
\hline Compound & $\begin{array}{l}\mathrm{FeCl}_{2} \cdot 4 \mathrm{H}_{2} \mathrm{O} \\
(0.2 \mathrm{M})\end{array}$ & $\begin{array}{l}\mathrm{NaOH} \\
(1 \mathrm{M})\end{array}$ & SDS \\
\hline 1 & $5.0 \mathrm{ml}$ & $2.0 \mathrm{ml}$ & $\begin{array}{l}0.5 \mathrm{ml} \\
(15 \mathrm{mM})\end{array}$ \\
\hline 2 & $5.0 \mathrm{ml}$ & $1.0 \mathrm{ml}$ & $\begin{array}{l}2.0 \mathrm{ml} \\
(15 \mathrm{mM})\end{array}$ \\
\hline 3 & $5.0 \mathrm{ml}$ & $1.0 \mathrm{ml}$ & $\begin{array}{l}0.5 \mathrm{ml} \\
(35 \mathrm{mM})\end{array}$ \\
\hline 4 & $5.0 \mathrm{ml}$ & $1.0 \mathrm{ml}$ & $\begin{array}{l}0.5 \mathrm{ml} \\
(35 \mathrm{mM})\end{array}$ \\
\hline 5 & $5.0 \mathrm{ml}$ & $1.5 \mathrm{ml}$ & $\begin{array}{l}0.5 \mathrm{ml} \\
(35 \mathrm{mM})\end{array}$ \\
\hline
\end{tabular}

The suspended magnetite/surfactant product was put in a sonication bath (Qualilab USR-30 H) for $1 \mathrm{~h}$. The suspension was then diluted with a 20 fold excess of distilled water before being sonicated again for $10 \mathrm{~min}$ and centrifuged (Heraeus Instruments, Labofuge 400) at $3500 \mathrm{~g}$ for $30 \mathrm{~min}$. The samples containing particles less than $100 \mathrm{~nm}$ in size were also filtered (NC10; Schleicher $\&$ Schuell) prior to sonication and centrifugation. The magnetite sediment was suspended in ethanol and sonicated for a few seconds and then "spotted" onto carbon coated copper grids of 400 mesh size for TEM examination and onto $1 \mathrm{~cm}$ squares of polished silicon wafers for SEM examination and then dried before analysis.

Scanning electron microscopy (SEM) measurements were performed using a LEO 1530 scanning electron microscope operating at $3 \mathrm{KeV}$. Transmission electron microscopy (TEM) measurements were performed using a Tecnai T20 ST transmission electron microscope operating at $200 \mathrm{KeV}$. 


\section{Results and Discussion}

The synthesis of magnetite in the presence of SDS under hydrothermal conditions has yielded a variety of structures, five of which are discussed here.

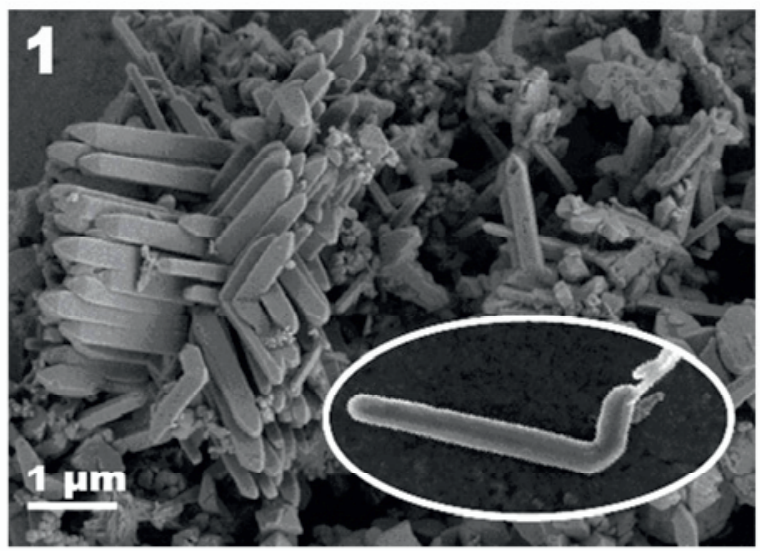

Figure 4. Bullet shaped needles frequently observed with $90^{\circ}$ bend.

Firstly, bullet shaped needles with an aspect ratio of $1: 6-8$ and $1-2 \mu \mathrm{m}$ in length with square-pyramidal endings (compound 1, Figure 4.) can be observed as aligned bundles and rather unusually these crystals frequently grow with a $90^{\circ}$ bend. Acicular magnetite and maghemite with similar aspect ratios and sizes is commonly used for magnetic media devices. However the route to obtaining these is not straightforward and typically involves the synthesis of goethite $(\alpha-\mathrm{FeOOH})$ or lepidocrocite $(\gamma-$ $\mathrm{FeOOH})$, followed by dehydration to form hematite ( $\alpha$ $\mathrm{Fe}_{2} \mathrm{O}_{3}$ ) and then reduction to magnetite. This can then be re-oxidised to give maghemite $\left(\gamma-\mathrm{Fe}_{2} \mathrm{O}_{3}\right)[16,17]$.

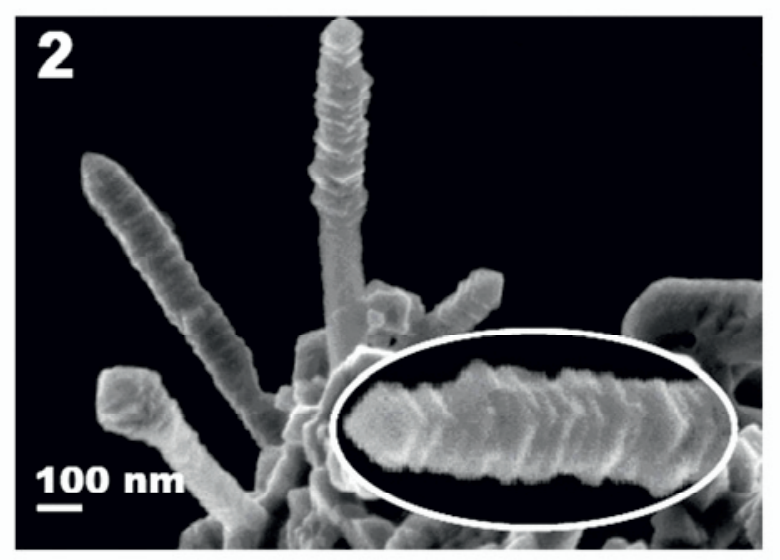

Figure 5. Ordered 1D array of nanocrystallites.

Arrays of magnetite octahedra (compound 2, Figure 5.) were observed having $80-100 \mathrm{~nm}$ dimensions forming 1D stacks of up to $4 \mu \mathrm{m}$ in length. Recently, very similar magneto-fossils formed by magnetotactic bacteria have been reported [18].
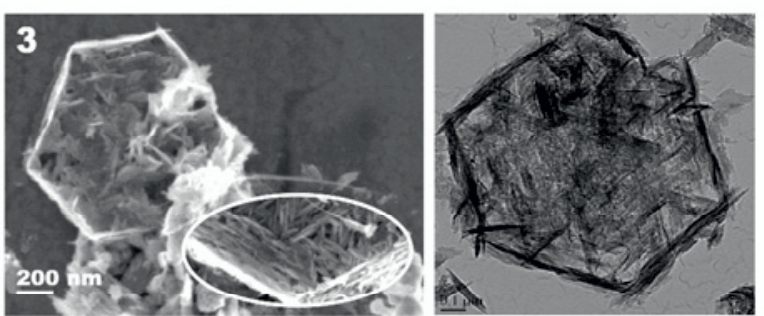

Figure 6a. SEM Overview and detail (inset) and Figure $\mathbf{6 b}$. TEM overview of whiskers forming $2 \mathrm{D}$ hexagonal plate motifs.

Whiskers with an aspect ratio 1:10 (compound 3, Figures 6a-c.), typically around $100-200 \mathrm{~nm}$ in length, also form and these self-assemble into 2D hexagonal plate and 3D "flower" motifs.

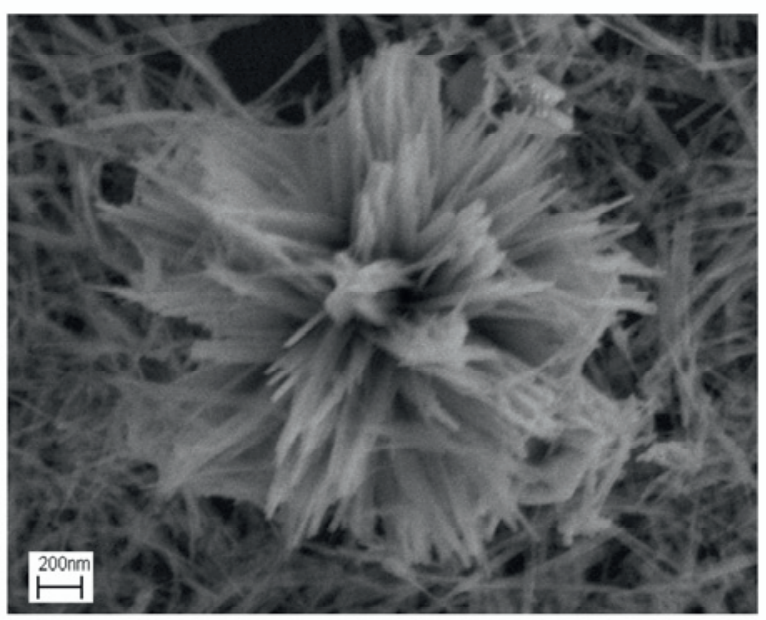

Figure 6c. SEM of magnetite whiskers in 3D flower motif.

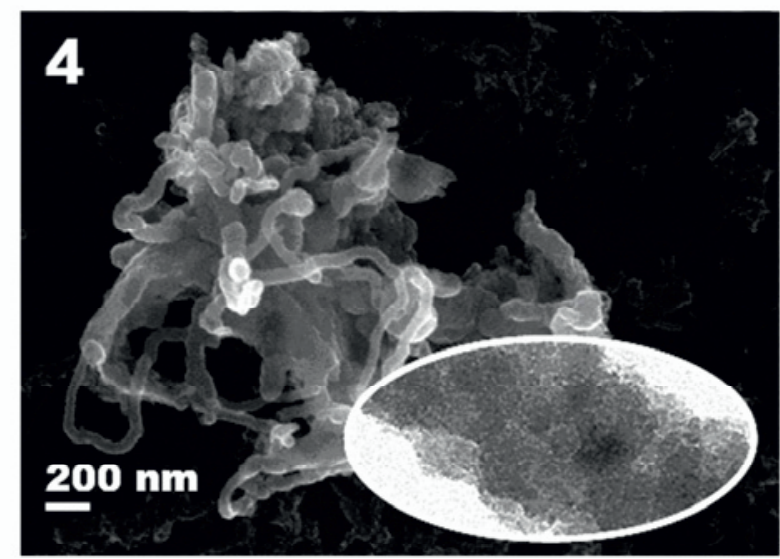

Figure 7. String-like assemblies composed of nanocrystallites.

String-like crystallite assemblies are observed (compound 4, Figure 7.) with the strings composed of nanocrystals less than $10 \mathrm{~nm}$ in diameter arranged in helical bundles of 70-200 nm in diameter and up to $5 \mu \mathrm{m}$ in length. These could possibly be related to the magnetite spheres reported by Hou et al. [19], the only other report of such unusual magnetite, which were 
prepared hydrothermally by reducing $\mathrm{Fe}[\mathrm{acac}]_{3}$ in the presence of various surfactants.

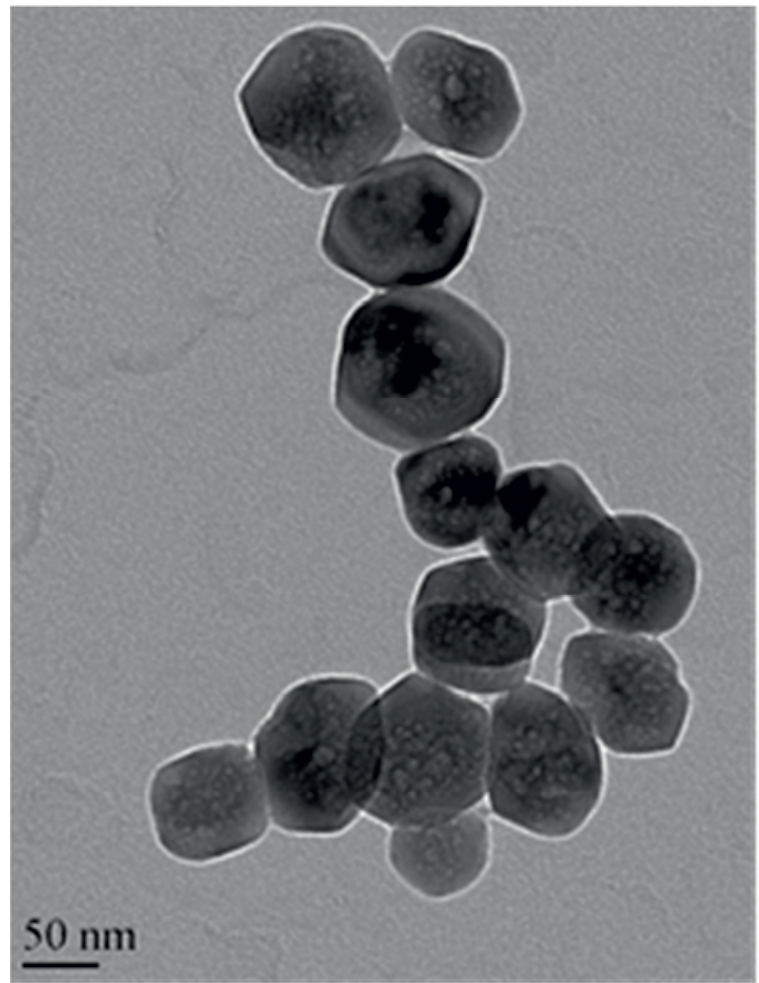

Figure 8. TEM of mesoporous magnetite nanocrystallites (compound 5).

Finally, mesoporous nanocrystallites form (compound 5, Figure 8.) with diameters of $40-100 \mathrm{~nm}$ and a morphology similar to the widely reported truncated dodecahedral shape seen in certain magnetotactic bacteria [12]. These nanocrystallites, like compound 3, also seem to self-align. The "question-mark" motif seen in Figure 8. is typical. It has been reported that magnetosome vesicles are present prior to magnetite formation in magnetotactic bacteria [20]. In this case a parallel could be drawn to the presence of SDS micelles and subsequent formation of nanocrystalline magnetite arrays. In addition to its "biogenic signature" this mesoporous nanomagnetite could be useful for targeted drug delivery [21].

\section{Conclusion}

These observations show that our method can lead to the production of a wide variety of unusual shapes of crystalline magnetite with the trademarks of those seen in biogenic magnetite as well as 1D, 2D and 3D ordering of the crystallites in some systems. Our observations of the formation of unusual crystalline magnetite is not limited to SDS and we have found that a wide variety of organic templates can be used including some of natural origin which we will be reporting in due course. Thus it would seem that it is possible for magnetite of geological origin to display unusual morphologies where such templates are available, suggesting that caution should be exercised in the classification of such mineral deposits as signatures for life forms.

The authors would like to thank the D.F.G. Center for Functional Nanostructures for financial support. They would also like to thank Harald Rösner (now at University of Münster) for assistance with the TEM.

\section{References}

1. Avicenna (Abu Ali Sina). Canon of Medicine (ca. 1000).

2. U. Häfeli, Magnetism in Medicine, Andrä, W. and Nowak, H. eds. Wiley-VCH, Weinheim, 5 (2007).

3. S. Mornet, et al., Progress in Solid State Chemistry 34, 237 (2006)

4. J.L. Kirschvink, A. Kobayashi-Kirschvink, and B.J. Woodford, Proc.Natl.Acad.Sci. USA 89, 7683 (1992).

5. D. Hautot, Q.A. Pankhurst, N. Khan, and J. Dobson, Proc. R. Soc. Lond. B (Suppl.) 270, S62 (2003).

6. C.J. Murphy, Nature Materials 6, 259 (2007)

7. R. Bratschitsch, and A. Leitenstorfer, Nature Materials 5, 855 (2006).

8. X. Yang, X., et al. Biochemistry 39, 4915 (2000).

9. R.B. Frankel, and R.P. Blakemore, Iron Biominerals, Plenum, New York, (1990).

10. R.B. Frankel, G.C. Papaefthymiou, R.P. Blakemore, and W. O'Brien. W. Biochemica et Biophysica Acta 763, 147 (1983).

11. D.L. Balkwil, D. Maratea, and R.P. Blakemore, J Bacteriol 141, 1399 (1980).

12. R.M. Cornell, and U. Schwertmann, The Iron Oxides, Wiley-VCH, Weinheim, (1996).

13. D. Schüler, Arch. Microbiol 181, 1 (2004).

14. M.N. Jones, Biological interfaces: An Introduction to the Surface and Colloid Science of Biochemical and Biological System, Elsevier, Amsterdam, (1975).

15. Q. Xu, and T.A. Keiderling, Protein Science 13, 2949 (2004).

16. K.H. Büchel, H.-H. Moretto, and P. Woditsch, Industrial Inorganic Chemistry, Wiley-VCH, Weinheim, 582, (2000)

17. M.P. Sharrock, and R.E. Bodnar, J. Appl. Phys. 57, 3919 (1985).

18. D. Schumann, et al., PNAS 105, 17648 (2008).

19. Y. Hou, S. Gao, T. Ohta, and H. Kondoh, Eur. J. Inorg. Chem. 6, 1169 (2004).

20. A. Komelli, H. Vali, T.J. Beveridge, and D.K. Newman, PNAS 101, 3839 (2004).

21. W. Andra, and H. Nowark H. Magnetism in Medicine, Wiley-VCH, Berlin, (1998). 